\title{
Implementasi Fuzzy C-Means Clustering dalam Pengelompokan UKM Di Kabupaten Rokan Hulu
}

\author{
Implementation of Fuzzy C-Means Clustering for Small and Medium Enterprise \\ In Rokan Hulu Regency \\ ${ }^{1}$ Erni Rouza, ${ }^{2}$ Luth Fimawahib \\ ${ }^{1,2}$ Teknik Informatika, Fakultas Ilmu Komputer, Universitas Pasir Pengaraian \\ Email: 1ernirouzait@gmail.com, luthfimawahib@gmail.com ${ }^{2}$
}

\begin{abstract}
Abstrak
Dalam upaya meningkatkan Usaha Kecil dan Menengah (UKM) di Kabupaten Rokan Hulu yang menjadi industri kreatif dan inovatif tentunya pendataan pesebaran UKM harus up to date dan valid sehingga pemerintah dapat memberikan kebijakan ataupun bantuan kepelaku usaha untuk mengembangkan usahanya apalagi dalam situasi pandemic ini. Penelitian ini bertujuan untuk mengelompokkan jenis UKM yang ada di Rokan Hulu menggunakan metode Fuzzy C-Means Clustering dan membuat aplikasi baru berbasis Web untuk mendata persebaran UKM yang dilengkapi dengan peta pesebaran UKM . Fuzzy C-Mean Clustering (FCM) adalah suatu teknik pengclusteran data yang mana keberadaan tiap-tiap titik data dalam suatu cluster ditentukan oleh derajat keanggotaannya. Variabel yang digunakan berdasarkan omset, asset dan jumlah tenaga kerja. Sedangkan untuk pengelompokan jenis UKM dicluster menjadi 3 jenis, yaitu usaha menengah, usaha kecil dan usaha mikro. Berdasarkan hasil pengujian metode Fuzzy C-Mean Clustering dapat mengelompokkan jenis Usaha Kecil Menengah berdasarkan 3 cluster yaitu usaha menengah, usaha kecil dan usaha mikro, serta nilai validasinya rata-rata hampir mendekati angka 1, hal tersebut menunjukkan bahwa Fuzzy C-Means Clustering memiliki tingkat akurasi yang tinggi sebesar $80-90 \%$.
\end{abstract}

Kata kunci: Fuzzy C-Mean Clustering, Usaha Kecil Menengah (UKM), Rokan Hulu

\begin{abstract}
To increase Small and Medium Enterprises (UKM) in Rokan Hulu Regency which become creative and innovative industries, of course the data collection on the distribution of UKM must be up to date and valid so that the government can provide policies or assistance to business actors to develop their businesses especially in this pandemic situation. This research aims to explore the potential of UKM and classify the types of UKM in Rokan Hulu and create a new application using the Fuzzy C-Mean Clustering method. Fuzzy C-Mean Clustering (FCM) is a data clustering technique in which the existence of each data point in a cluster is determined by the degree of its membership. The variable that used based of income, asset, and total man power while to classificasion type of small and medium Enterprises that cluster to be three kind, Medium Enterprises ,Small Enterprises, and Micro Enterprises. Based of examination methode Fuzzy CMean Clustering can classification type of Small and Medium Enterprises based of 3 cluster that Medium Enterprises, Small Enterprises, Micro Enterprises and than validation scorce almost one numbered, for those show that Fuzzy C-Means Clustering have high acuration level in 80-90 $\%$.
\end{abstract}

Keywords: Fuzzy C-Mean Clustering, Small and Medium Enterprises (UKM), Rokan Hulu

\section{PENDAHULUAN}

Di era revolusi 4.0 para pelaku Usaha Kecil dan Menengah (UKM) harus mampu beradaptasi dengan teknologi berbasis digital, karena proses penjualan maupun promosi produk, barang maupun jasa pada UKM via konvensional sudah tidak efektif dan mulai ditinggalkan oleh 
pelaku usaha apalagi dengan adanya pandemic covid-19 ini. Kabupaten Rokan Hulu merupakan salah satu kabupaten yang ada di provinsi Riau, Pasir Pengaraian menjadi ibu kota dari kabupaten Rokan Hulu, saat ini kota Pasir Pengaraian banyak mengalami perubahan, baik dari segi tata kelola kota, ekonomi, bahkan budaya. Investasi semakin meningkat khususnya dibidang UKM. Tercatat bahwasanya tahun 2015, jumlah pengurusan izin usaha dari sektor Usaha Kecil dan Menengah (UKM) meningkat $10 \%$ dibandingkan 2014 yakni 5000 berkas izin usaha, dari 5000 berkas izin Usaha, UKM dibidang perdagangan seperti usaha kuliner, rata-rata setiap tahun naik 7\% hingga 10\%.[1]. Untuk menjadi industri yang kreatif dan inovatif di era revolusi 4.0 ini, kehadiran pemerintah terkait maupun KADIN (Kamar Dagang Indonesia) sangat dibutuhkan untuk mendorong agar semua pelaku usaha mau mendaftarkan dan melaporkan usahanya sehingga sistem yang sudah terdigitalisasi saling terkoneksi antar pelaku usaha. Sehingga pemerintah dapat memberikan bantuan ataupun meminjamkan dana dengan tepat sasaran.

Berdasarkan analisis data yang diperoleh dari Instansi terkait, masih ditemukan beberapa data pengelompokan jenis usaha UKM yang belum tepat pengelompokannya berdasarkan jumlah aset usaha menurut Undang-undang No 20 Tahun 2008 tentang UMKM, karena proses pengelompokan data UKM masih bersifat manual dan diketik pada Microsoft Excell, sehingga terdapat kesalahan pengelompokan yaitu pada usaha mikro asset usaha. Untuk lebih jelasnya dapat dilihat pada tabel 1. Kriteria UMKM (Usaha Mikro Kecil Menengah) berdasarkan UU No 20 Tahun 2008.

Tabel 1. Kriteria UKM Berdasarkan Undang-Undang No 20 Tahun 2008

\begin{tabular}{|c|c|c|c|}
\hline \multirow{2}{*}{ No } & \multirow{2}{*}{ Uraian } & \multicolumn{2}{|c|}{ Kriteria } \\
\cline { 3 - 4 } & & Aset & Omset \\
\hline 1. & Usaha Mikro & Maksimal 50 juta & Maksimal 300 juta \\
\hline 2. & Usaha Kecil & $>50$ Juta-500 Juta & $>300$ Juta-2,5 M \\
\hline 3. & Usaha Menengah & $>500$ Juta- 10 M & $>2,5 \mathrm{M}-50 \mathrm{M}$ \\
\hline
\end{tabular}

Sedangkan untuk contoh sebagian data wirausaha Kabupaten Rokan Hulu terdapat pada tabel 2 dan pengelompokan jenis usaha yang belum tepat ditandai dengan tulisan berwarna merah.

Tabel 2. Sebagian Data Wirausaha Kabupaten Rokan Hulu

\begin{tabular}{|c|c|c|c|c|c|c|c|c|c|}
\hline No & NAMA PEMILIK & NAMA USAHA & ALAMAT & $\begin{array}{l}\text { SKALA } \\
\text { USAHA }\end{array}$ & SEKTOR USAHA & $\begin{array}{c}\text { JUMLAH } \\
\text { TENAGA KERJA }\end{array}$ & JUMLAH ASET & JUMLAH OMSET & KET \\
\hline 32 & SUMARNO & PERON SUMARNO & Kumu Baru & KECIL & Produksi & 5 & 190.000 .000 & 400.000 .000 & \\
\hline 33 & TUKIRIN & SUMBER URIP & Kumu Deli & KECIL & Industri & 4 & 132.100 .000 & 200.000 .000 & \\
\hline 34 & YUSKIMAR & CV. MALAFARI FANEL & Rambah & KECIL & Kontruksi & 9 & 145.000 .000 & 175.000 .000 & \\
\hline 35 & SUWARNO & UD. MITRA TANI & DU SKPD & KECIL & PERDAGANGAN & 3 & 100.000 .000 & 185.000 .000 & \\
\hline 36 & SITI KHOIRIYAH & BUMDES BINA USAHA & Desa Sunagai Sitolang & Menengah & Jasa & 20 & 598.000 .000 & 857.079 .352 & \\
\hline 37 & ROBRT & TRS SAWIT ANUIGAH & Simona & 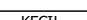 & Droduci(TRC) & & 146000000 & & \\
\hline 31 & RUBBI & IBS SAWII ANUGRAH & Simpang $D$ & KECIL & Produksi(TBS) & 9 & 146.000 .000 & 200.000 .000 & \\
\hline 38 & SYAHLAN & IKHLAS & Desa Muara Musu & KECIL & PERDAGANGAN & 5 & 99.001 .100 & 150.000 .000 & \\
\hline 39 & NASIRIN & MELA PELAMINAN & Desa Rambah Muda & KECIL & Jasa & 15 & 137.900 .000 & 200.000 .000 & \\
\hline 40 & SOPAN FAUZI & TBS. TIWI JELIA & Desa Pasir Utama & Fecil & Produksi(TRS) & 5 & 440000000 & 600000000 & \\
\hline & & & Desa Pasi Vulanda & Kecli & Produksi (TBS) & 5 & 440.000 .000 & 600.000 .000 & \\
\hline 41 & ABDUL AZIS & SAE NIKI & Simpang D & Kecil & Industri & 10 & 80.000 .000 & 175.000 .000 & \\
\hline 42 & JAJA & UD. KURNIA PUTRA & Desa Sungai Sitolang & Kecil & Kontruksi & 7 & 117.100 .000 & 200.000 .000 & \\
\hline 43 & HASAN BASRI & SY HIDAYAT BANGUIAN & Mйа Мияч & Kecil & Kontrukei & 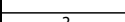 & 1500000000 & 300000000 & \\
\hline 43 & HASAN BASRI & CV. HIDAYAT BANGUNAN & Muara Musu & Kecil & Kontruksi & 2 & 150.000 .000 & 300.000 .000 & \\
\hline 44 & SERMIN SITUMORANG & APOTIK TIARA & Simpang D & Kart & PERDAGANGAN & 6 & & 150.000 .000 & \\
\hline 45 & PERLINDUNGAN LUMBAN & TOKO MAJU BERSAMA & Simpang D & Menengah & PERDAGANGAN & 7 & 634.200 .000 & 1.000 .000 .000 & \\
\hline 46 & DFVIARISANDI & TOKO OBATAN ADIB & KumuSeizti & Foct & PERDAGANGAN & 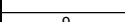 & 120200000 & 200000000 & \\
\hline 40 & DEVI ARISANDI & & Kumu Sejati & Kecil & PERDAGANGAN & 9 & 134.200 .000 & 200.000 .000 & \\
\hline 47 & SAMSURIJAL IS & TOKO BANGUNAN FARIRA & Pasar Muara Rumbai & Kecil & Kontruksi & 4 & 75.260 .000 & 100.000 .000 & \\
\hline 48 & FADLI & TOKO DEL SERDANG & Suka Mulya & Kecil & PERDAGANGAN & 7 & 72.000 .000 & 100.000 .000 & \\
\hline 49 & UUN & KEDAI UUN & DS PASIR JAYA & & PERTANIAN & 4 & & 100.000 .000 & \\
\hline & & & & & & & & & \\
\hline 50 & PAINTEN & KEDAI PAINTEN & D4 SKPC & & PERDAGANGAN & 6 & & 160.000 .000 & \\
\hline
\end{tabular}

Sumber: Koperindak Rokan Hulu 2015

Untuk mengatasi hal tersebut maka pada penelitian ini penulis mencoba menerapkan suatu metode untuk dapat mengclusterkan jenis UKM yang ada di Rokan hulu sesuai dengan Undang-undang No 20 Tahun 2008. Metode tersebut adalah metode Fuzzy C-means Clustering 
(FCM). Clustering merupakan proses pengelompokan data dalam kelas-kelas atau cluster-cluster sehingga data dalam suatu cluster memiliki tingkat persamaan yang tinggi satu dengan lainnya tetapi sangat berbeda dengan data dalam cluster lain. [2]. Salah satu soft-clustering yang sangat populer adalah fuzzy c-mean, yaitu suatu algoritma pengklasteran yang mencari pusat-pusat klaster dengan meminimumkan fungsi ketidakmiripan [3]. Sedangkan Fuzzy C-means Clustering (FCM), atau dikenal juga sebagai Fuzzy ISODATA, merupakan salah satu metode clustering yang merupakan bagian dari metode Hard K-Means. Menurut Kusuma dkk [4] FCM menggunakan model pengelompokan fuzzy sehingga data dapat menjadi anggota dari semua kelas atau cluster terbentuk dengan derajat atau tingkat keanggotaan yang berbeda antara 0 hingga 1 . Sedangkan hasil penelitian [5], Fuzzy C-Means memiliki tingkat akurasi yang tinggi dan waktu komputasi yang tepat.

Sutoyo dan Sumpala [5], menggunakan Fuzzy C-means untuk mendeteksi secara dini kemampuan penalaran Matematis, indikator ataupun variabel yang digunakan pada penelitian ini dikatagorikan kedalam 3 katagori, yaitu; baik, cukup dan kurang. Dari hasil perhitungan diperoleh 11 orang (25\%) yang memiliki kemampuan penalaran matematis baik, sebanyak 25 orang (57\%) memiliki kemampuan penalaran matematis cukup, dan sebanyak $8(18 \%)$ orang memiliki kemampuan penalaran matematis yang kurang.

Pada penelitian Dewi Astria dan Suprayogi [6] menggunakan Fuzzy C-means Clustering (FCM) untuk mengcluster pelanggan pada CV. Mataram Jaya Bawen. Pada penelitian tersebut Pelanggan dibagi menjadi 4 cluster pelanggan yaitu Golden, Silver, Bronze, dan Iron dengan variabel yang dijadikan acuan adalah tanggal pembelian akhir, frequensi beli dan total pembelian. Data yang digunakan merupakan data transaksi pelanggan periode September - Desember 2015. Total data adalah 709 transaksi dari 75 pelanggan. Setelah data tersebut diolah dengan metode Fuzzy C-Means, hasil akhir menunjukkan iterasi berakhir pada iterasi ke - 30 dengan perubahan fungsi objektif sebesar 9.8. Cluster pelanggan yang dihasilkan adalah Golden : 27, Silver : 15, dan Bronze : 33 dengan validitas cluster sebesar 0.596277. Sedangkan Rio Ferdiansyah dkk [7] merancang dan membangun aplikasi untuk klasisfikasi usaha mikro home industry ikan kering di daerah pesisir Kota Bengkulu berbasis web, usaha tersebut dibagi menjadi tiga kelompok, yaitu skala kecil, skala menengah, dan skala besar dengan menggunakan 7 kriteria, hasil yang diperoleh berupa aplikasi yang mempermudah pengelompokan data kualitatif usaha mikro home industri ikan kering di daerah pesisir Kota Bengkulu.

Penelitian ini bertujuan untuk mengelompokkan jenis UKM yang ada di Rokan Hulu menggunakan metode Fuzzy C-Means Clustering dan membuat aplikasi baru berbasis Web untuk mendata persebaran UKM yang dilengkapi dengan peta pesebaran UKM. Maka berdasarkan uraian diatas, pada penelitian ini lebih difokuskan pada pengelompokan dan mengidentifikasikan jenis UKM yang ada di Rokan Hulu, dengan judul Implementasi Fuzzy C-Means Clustering dalam Pengelompokan UKM Di Kabupaten Rokan Hulu.

\section{METODE PENELITIAN}

Data mining adalah proses menemukan pola yang menarik dan pengetahuan dari sejumlah besar data. Sumber data dapat mencakup database, gudang data, web, repositori informasi lainnya, atau data yang dialirkan ke dalam sistem dinamis [8]. Pelaksanaan penelitian dalam menerapkan Fuzzy C-Means Clustering dalam Pengelompokan UKM Di Kabupaten Rokan Hulu menggunakan model CRIPS-DM (Cross Industri Standart Process For Data Mining). 


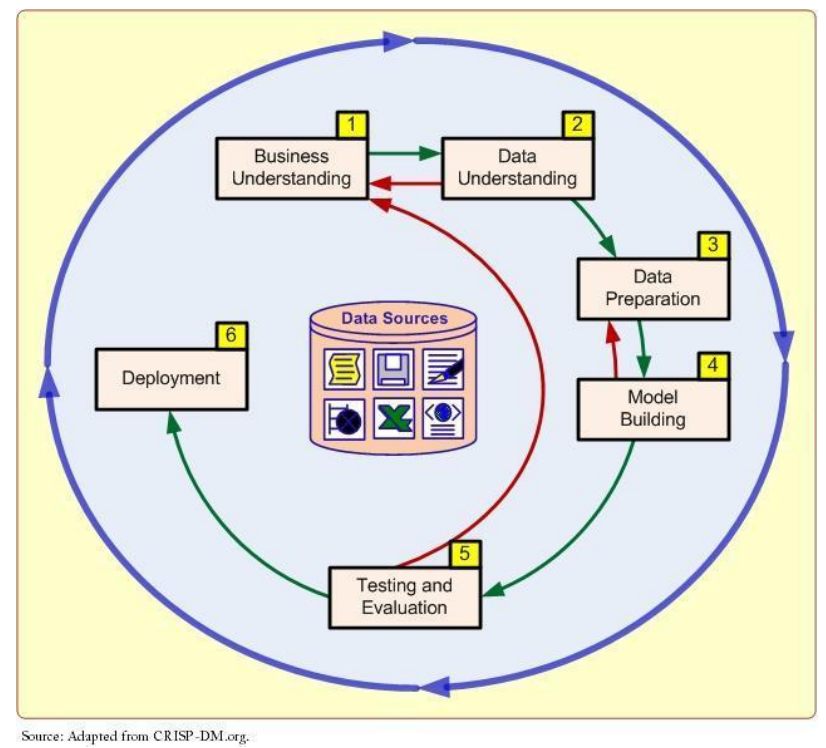

Gambar 1. Siklus Model Cross Industri Standart Process For Data Mining

Langkah yang dilakukan yaitu

1. Fase Bisnis (Business Understanding) :

Meliputi penentuan tujuan dari penelitian, mengidentifikasi dan menganalisa bahkan menilai situasi saat ini, menetapkan tujuan data mining dan mengembangkan proyek. Tujuan bisnis yang dilakukan dalam penelitian ini adalah pengelompokkan jenis UKM dengan menggunakan metode Fuzzy C-Means Clustering

2. Fase Pemahaman Data (Data Understanding Phase) :

Setelah tujuan bisnis dan rencana proyek ditetapkan, langkah selanjutnya melakukan pengumpulan data awal, deskripsi data, eksplorasi data dan verifikasi kualitas data. Data tersebut berasal dari instansi terkait, jurnal-jurnal, buku-buku, baik itu berupa data primer maupun data sekunder. Adapun data yang digunakan pada penelitian ini berasal dari data UMKM Rokan Hulu tahun 2015 yang berjumlah 1531 UMKM dan dibatasi hanya 150 data yang diambil secara acak untuk perhitungan manual sebanyak 15 data serta data uji pada aplikasi sebanyak 150 data.

3. Fase Pengolahan Data (Data Preparation Phase) :

Pada tahap ini dilakukan identifikasi dan pembangunan jawaban dari data yang telah dikumpulkan untuk bisa melakukan pengelompokkan dan pemilahan ke dalam kelompok-kelompok yang telah ditentukan. Identifikasi data variable dan cluster dapat terdapat pada tabel 3 .

Tabel 3 Data Variabel dan data Cluster
\begin{tabular}{|c|c|c|c|}
\hline \multicolumn{2}{|c|}{ Variabel } & \multicolumn{2}{c|}{ Cluster } \\
\hline $\mathrm{X}_{\mathrm{i}}$ & Aset Usaha & Cluster 1 & Usaha Menengah \\
\hline $\mathrm{X}_{2}$ & Omset Usaha & Cluster 2 & Usaha Kecil \\
\hline $\mathrm{X}_{3}$ & Tenaga Kerja & Cluster 3 & Usaha Mikro \\
\hline
\end{tabular}

4. Fase Pemodelan (Modeling Phase) : Pada fase ini dilakukan pemilihan model yang akan digunakan untuk melakukan pengelompokan jenis UKM, dalam penelitian ini model yang dipilih adalah Fuzzy C-Means Clustering dan diimplementasikan kedalam bentuk aplikasi berbasis web yang dilengkapi peta dengan memanfaatkan google Maps API untuk pesebaran UKM. Adapun algoritma dari Fuzzy C-Means Clustering sebagai berikut [9];

1. Masukkan data yang akan di cluster $\mathrm{X}$, berupa matrik berukuran $\mathrm{n} \times \mathrm{m}(\mathrm{n}=$ jumlah sampel data, $m=$ atribut setiap data). $X i j=$ data sampel ke-i $(i=1,2, \ldots, n)$, atribut ke-j $(\mathrm{j}=1,2, \ldots, \mathrm{m})$.

2. Tentukan :

a. Jumlah cluster $=\mathrm{c}$; 

b. Pangkat $=\mathrm{w}$;
c. Maksimum iterasi = MaxIter;
d. Error terkecil yang diharapkan $=\varepsilon$;
e. Fungsi objektif awal $=\mathrm{P} 0=0$;
f. Iterasi awal $=\mathrm{t}=0$;

3. Bangkitkan bilangan random $\mu_{i k}$ sebagai elemen matriks partisi awal U.

$$
\text { Rumus: } \sum_{j=1}^{k} \mu_{i j}=1(1)
$$

4. Hitung pusat cluster ke-k: $\mathrm{V}_{k j}$. Dengan $k=1,2, \ldots, \mathrm{c}$ dan $j=1,2, . ., \mathrm{m}$

$$
\text { Rumus: } V_{k j}=\frac{\sum_{i=1}^{n}\left(\left(\mu_{i k}\right)^{w} * X_{i j}\right)}{\sum_{i=1}^{n}\left(\mu_{i k}\right)^{w}}(2)
$$

5. Hitung fungsi objektif pada iterasi ke-t:

$$
\text { Rumus: } \left.P_{t}=\sum_{i=1}^{n} \sum_{k=1}^{C}\left(\left[\sum_{j=1}^{m} X_{i j}-V_{k j}\right)^{2}\right]\left(\mu_{i k}\right)^{w}\right)
$$

6. Hitung perubahan matriks partisi dan perubahan matrik partisi $U$

7. Cek kondisi berhenti,

$$
\text { Rumus: } \mu_{i k}=\frac{\left[\sum_{j=1}^{m}\left(X_{i j}-V_{k j}\right)^{2}\right]^{\frac{-1}{w-1}}}{\sum_{k=1}^{C}\left[\sum_{j=1}^{m}\left(X_{i j}-V_{k j}\right)^{2}\right]^{\frac{-1}{w-1}}}
$$

$$
\begin{aligned}
& \text { a. Jika : }(|\mathrm{Pt}-\mathrm{Pt}-1|<\varepsilon) \text { atau }(\mathrm{t}<\text { MaxIter }) \text { maka berhenti; } \\
& \text { b.Jika tidak }: \mathrm{t}=\mathrm{t}+1 \text {, ulangi langkah ke- } 4 \text {. } \\
& \text { Dimana, } \mathrm{Pt}=\text { Fungsi Objektif pada iterasi ke } \mathrm{t}, \mathrm{t}=\text { Iterasi ke } \\
& \text { MaxIter = Iterasi maksimum }
\end{aligned}
$$

5. Fase Evaluasi (Evaluation Phase) : Pengujian akan dilakukan dengan membandingkan pengelompokkan yang dilakukan oleh algoritma Fuzzy C-Means Clustering dengan pengelompokkan oleh pihak terkait. Pada fase ini juga diadakan evaluasi dan pengujian pada aplikasi yang dibangun. Diharapkan hasil pengujian dan pencocokan data dari aplikasi yang telah dibangun menggunakan algoritma Fuzzy C-Means Clustering dapat mengelompokkan jenis usaha sesuai dengan Undang-Undang No. 20 Tahun 2008.

6. Fase Deployment (Deployment Phase): pada tahapan ini dilakukan proses presentasi aplikasi yang telah dibangun dan membuat laporan akhir dari implementasi tersebut. Dalam tahapan ini juga melibatkan user yang akan menggunakan aplikasi data mining, dalam hal ini yaitu aplikasi berbasis web menggunakan Fuzzy C-Means Clustering untuk mengelompokkan jenis usaha kecil menengah (UKM).

\section{HASIL DAN PEMBAHASAN}

\subsection{Implementasi metode Fuzzy C-Means Clustering}

Data yang digunakan dalam proses implementasi metode Fuzzy C-Means Clustering untuk pengelompokan jenis UKM di Kabupaten Rokan Hulu berasal dari data UMKM Rokan hulu tahun 2015, dan hanya data sebanyak 165 data UKM yang diambil secara acak, untuk perhitungan manual sebanyak 15 data serta data uji pada aplikasi sebanyak 150 data. Data-data tersebut akan dikelompokkan ke dalam 3 cluster sesuai dengan variabel yang telah ditentukan, yaitu variabel omset, asset dan tenaga kerja. Untuk flowchart proses implementasi Fuzzy C-Means Clustering dapat dilihat pada gambar 2 . 


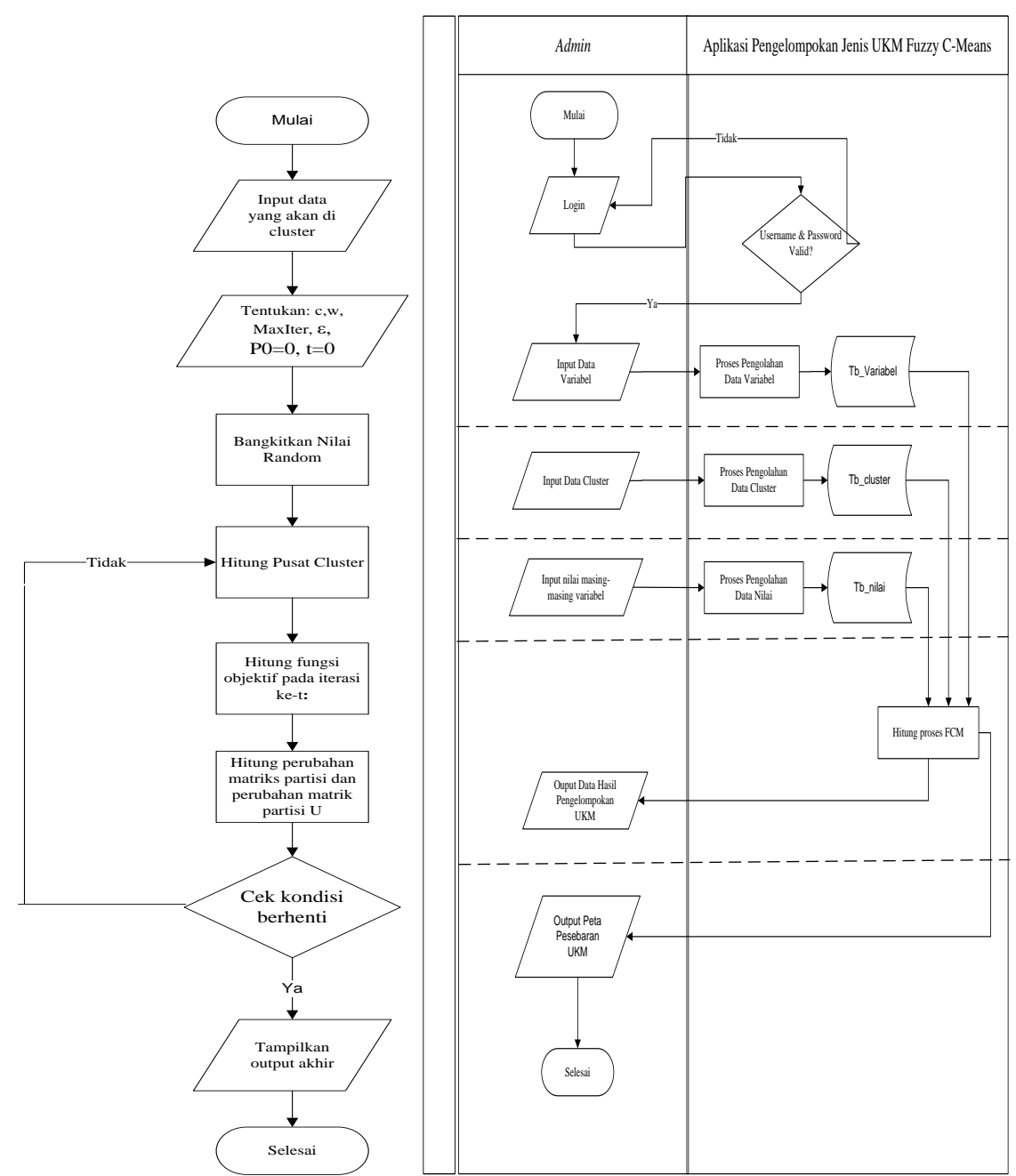

Gambar 2. Flowchart Algoritma Fuzzy C-Means Clustering dan Flowchart Aplikasi

Dari flowchart yang ada pada gambar 2, terlihat bahwasanya data yang akan di klaster dimasukkan terlebih dahulu, kemudian dibangkitkan dengan nilai random dimana hasil penjumlahan nilai disetiap recordnya akan bernilai 1 , proses selanjutnya hitung fungsi objektif pada setiap iterasi, hitung perubahan matrik, hingga menghasilkan hasil klaster tiap data, setelah data tersebut di kelompokkan kemudian baru ditampilkan dalam bentuk peta pesebaran UKM di Rokan Hulu.

3.2. Perhitungan Manual Implementasi Fuzzy C-Means Clustering dalam Pengelompokan Jenis UKM di Kabupaten Rokan Hulu

Proses perhitungan manual yang dilakukan menggunakan aplikasi Microsoft Excell untuk mencari iterasi-iterasi yang terbentuk dari proses penerapan metode Fuzzy C-Means Clustering ke studi kasus. Adapun tahapan penerapan metode sesuai dengan algoritma Fuzzy C-Means Clustering yaitu;

1. Untuk contoh perhitungan manual diambil 15 data dari data usaha kecil dan menengah (UKM) Kabupaten Rokan Hulu yang diambil secara random berdasarkan omset, asset dan tenaga kerja yang akan dijadikan cluster. 
Tabel 4. Data UKM Kecamatan Rambah Kabupaten Rokan Hulu

\begin{tabular}{|c|r|r|c|}
\hline & \multicolumn{1}{|c|}{ X1 (Rp) } & \multicolumn{1}{c|}{ X2 (Rp) } & X3 (Orang) \\
\hline Nama Usaha & \multicolumn{1}{c|}{ Omset } & \multicolumn{1}{c|}{ Aset } & Tenaga Kerja \\
\hline Perdagangan TBS & 100.000 .000 & 50.000 .000 & 4 \\
\hline Komawar & 250.000 .000 & 195.000 .000 & 2 \\
\hline Prima Motor & 600.000 .000 & 500.000 .000 & 12 \\
\hline Ikan Hiyas & 24.000 .000 & 20.000 .000 & 2 \\
\hline Fres Roo & 125.000 .000 & 100.000 .000 & 3 \\
\hline Toko Pincuran & 234.000 .000 & 1.000 .000 .000 & 3 \\
\hline Toko Abah Elektronik & 175.000 .000 & 80.000 .000 & 8 \\
\hline Toko Murni Diesel & 988.000 .000 & 500.000 .000 & 4 \\
\hline CV. Wijaya Enginering & 243.000 .000 & 110.000 .000 & 7 \\
\hline Toko Nasco & 250.000 .000 & 150.000 .000 & 3 \\
\hline Doa Ibu & 180.000 .000 & 60.000 .000 & 5 \\
\hline Apotek Mitra Harum & 280.000 .000 & 150.000 .000 & 12 \\
\hline Rental Mobil & 60.000 .000 & 50.000 .000 & 1 \\
\hline Toko Rental & 45.000 .000 & 20.000 .000 & 5 \\
\hline Cv. Dua Putri & 1.200 .000 .000 & 500.000 .000 & 6 \\
\hline
\end{tabular}

2. Kemudian menentukan :

Sumber: Koperindak Rokan Hulu 2015

1. Jumlah cluster $=\mathrm{c}$;

2. Pangkat $=\mathrm{w}$;

3. Maksimum iterasi = MaxIter;

4. Error terkecil yang diharapkan $=\varepsilon$;

5. Fungsi objektif awal $=\mathrm{P} 0=0$;

6. Iterasi awal $=\mathrm{t}=0$;

Tabel 5. Penentuan Nilai Awal

\begin{tabular}{|c|c|}
\hline \multicolumn{2}{|c|}{ Nilai Awal } \\
\hline Jumlah Cluster & 3 \\
\hline Pangkat (w) & 2 \\
\hline Max Iterasi & - \\
\hline Error Terkecil & 0,1 \\
\hline Fungsi Objektif Awal & 0 \\
\hline Literasi Awal & 1 \\
\hline
\end{tabular}

3. Setelah menentukan nilai awal kemudian bangkitkan bilangan random $\mu_{i k}$ sebagai elemen matriks partisi awal U, dengan menggunakan rumus (1), hasil dapat dilihat pada tabel 6 .

Tabel 6. Bilangan Random $\mu_{i k}$

$\mathrm{U}=$\begin{tabular}{|c|c|c|c|c|}
\hline No & \multicolumn{3}{|c|}{ Partisi Awal } & Jumlah \\
\hline 1 & 0,2 & 0,3 & 0,5 & 1 \\
\hline 2 & 0,1 & 0,4 & 0,5 & 1 \\
\hline 3 & 0,3 & 0,6 & 0,1 & 1 \\
\hline 4 & 0,8 & 0,1 & 0,1 & 1 \\
\hline 5 & 0,7 & 0,2 & 0,1 & 1 \\
\hline 6 & 0,4 & 0,3 & 0,3 & 1 \\
\hline 7 & 0,4 & 0,5 & 0,1 & 1 \\
\hline 8 & 0,6 & 0,2 & 0,2 & 1 \\
\hline 9 & 0,4 & 0,4 & 0,2 & 1 \\
\hline 10 & 0,1 & 0,3 & 0,6 & 1 \\
\hline 11 & 0,5 & 0,3 & 0,2 & 1 \\
\hline 12 & 0,6 & 0,1 & 0,3 & 1 \\
\hline 13 & 0,1 & 0,1 & 0,8 & 1 \\
\hline 14 & 0,2 & 0,1 & 0,7 & 1 \\
\hline 15 & 0,4 & 0,2 & 0,4 & 1 \\
\hline
\end{tabular}


Pada tabel 6 dapat dilihat partisi awal yang ada dikolom i,j dan k, jika di jumlahkan nilainya sama dengan 1. Bilangan random $\boldsymbol{\mu}_{i k}$ ini digunakan sebagai elemen untuk partisi awal matriks U.

4. Hitung pusat cluster $\mathrm{ke}-\mathrm{k}$ : $\mathrm{V}_{k j}$. Dengan $k=1,2, \ldots, \mathrm{c}$ dan $j=1,2, . ., \mathrm{m}$

Tabel 7. Perhitungan Pusat Cluster Derajat Keanggotaan Ke-1

\begin{tabular}{|c|c|c|c|c|c|c|c|}
\hline \multicolumn{8}{|c|}{ PERHITUNGAN PUSAT CLUSTER } \\
\hline \multirow{2}{*}{$\begin{array}{c}\text { Derajat Keanggotaan Pada } \\
\text { Cluster Ke-1 }\end{array}$} & \multicolumn{3}{|c|}{ Data yang di Cluster } & \multirow{2}{*}{$\left(\mathrm{m}_{\mathrm{i} 1}\right)^{2}$} & \multirow{2}{*}{$\left(\mathrm{m}_{\mathrm{i} 1}\right)^{2 *} \mathrm{X}_{1}$} & \multirow{2}{*}{$\left(\mathrm{m}_{\mathrm{i} 1}\right)^{2 *} \mathrm{X}_{2}$} & \multirow{2}{*}{$\left(m_{i 1}\right)^{2 *} X_{3}$} \\
\hline & $\mathrm{X} 1$ & $\mathrm{X} 2$ & $\mathrm{X} 3$ & & & & \\
\hline 0,2 & 1,00 & 0,50 & 4 & 0,04 & 0,04 & 0,02 & 0,16 \\
\hline 0,1 & 2,50 & 1,95 & 2 & 0,01 & 0,025 & 0,0195 & 0,02 \\
\hline 0,3 & 6,00 & 5,00 & 12 & 0,09 & 0,54 & 0,45 & 1,08 \\
\hline 0,8 & 0,24 & 0,20 & 2 & 0,64 & 0,1536 & 0,128 & 1,28 \\
\hline 0,7 & 1,25 & 1,00 & 3 & 0,49 & 0,6125 & 0,49 & 1,47 \\
\hline 0,4 & 2,34 & 10,00 & 3 & 0,16 & 0,3744 & 1,6 & 0,48 \\
\hline 0,4 & 1,75 & 0,80 & 8 & 0,16 & 0,28 & 0,128 & 1,28 \\
\hline 0,6 & 9,88 & 5,00 & 4 & 0,36 & 3,5568 & 1,8 & 1,44 \\
\hline 0,4 & 2,43 & 1,10 & 7 & 0,16 & 0,3888 & 0,176 & 1,12 \\
\hline 0,1 & 2,50 & 1,50 & 3 & 0,01 & 0,025 & 0,015 & 0,03 \\
\hline 0,5 & 1,80 & 0,60 & 5 & 0,25 & 0,45 & 0,15 & 1,25 \\
\hline 0,6 & 2,80 & 1,50 & 12 & 0,36 & 1,008 & 0,54 & 4,32 \\
\hline 0,1 & 0,60 & 0,50 & 1 & 0,01 & 0,006 & 0,005 & 0,01 \\
\hline 0,2 & 0,45 & 0,20 & 5 & 0,04 & 0,018 & 0,008 & 0,2 \\
\hline \multirow[t]{3}{*}{0,4} & 12,00 & 5,00 & 6 & 0,16 & 1,92 & 0,8 & 0,96 \\
\hline & \multicolumn{3}{|c|}{$\Sigma$} & 2,94 & 9,3981 & 6,3295 & 15,1 \\
\hline & \multicolumn{4}{|c|}{$\mathrm{a}\left[\left(\mathrm{m}_{\mathrm{i} 1}{ }^{2}\right) * \mathrm{X}_{\mathrm{ij}}\right] / \mathrm{a}\left(\mathrm{m}_{\mathrm{i} 1}{ }^{2}\right)$} & 3,196632653 & 2,152891156 & 5,136054422 \\
\hline
\end{tabular}

Tabel 8. Perhitungan Pusat Cluster Derajat Keanggotaan Ke-2

\begin{tabular}{|c|c|c|c|c|c|c|c|}
\hline \multicolumn{8}{|c|}{ PERHITUNGAN PUSAT CLUSTER } \\
\hline \multirow{2}{*}{$\begin{array}{l}\text { Derajat Keanggotaan Pada } \\
\text { Cluster Ke-2 }\end{array}$} & \multicolumn{3}{|c|}{ Data yang di Cluster } & \multirow{2}{*}{$\left(\mathrm{m}_{\mathrm{i} 1}\right)^{2}$} & \multirow{2}{*}{$\left(m_{i 1}\right)^{2 *} X_{1}$} & \multirow{2}{*}{$\left(\mathrm{m}_{\mathrm{il}}\right)^{2 *} \mathrm{X}_{2}$} & \multirow{2}{*}{$\left(m_{i 1}\right)^{2} * X_{3}$} \\
\hline & $\mathrm{X} 1$ & $\mathrm{X} 2$ & $\mathrm{X} 3$ & & & & \\
\hline 0,3 & 1,00 & 0,50 & 4 & 0,09 & 0,09 & 0,045 & 0,36 \\
\hline 0,4 & 2,50 & 1,95 & 2 & 0,16 & 0,4 & 0,312 & 0,32 \\
\hline 0,6 & 6,00 & 5,00 & 12 & 0,36 & 2,16 & 1,8 & 4,32 \\
\hline 0,1 & 0,24 & 0,20 & 2 & 0,01 & 0,0024 & 0,002 & 0,02 \\
\hline 0,2 & 1,25 & 1,00 & 3 & 0,04 & 0,05 & 0,04 & 0,12 \\
\hline 0,3 & 2,34 & 10,00 & 3 & 0,09 & 0,2106 & 0,9 & 0,27 \\
\hline 0,5 & 1,75 & 0,80 & 8 & 0,25 & 0,4375 & 0,2 & 2 \\
\hline 0,2 & 9,88 & 5,00 & 4 & 0,04 & 0,3952 & 0,2 & 0,16 \\
\hline 0,4 & 2,43 & 1,10 & 7 & 0,16 & 0,3888 & 0,176 & 1,12 \\
\hline 0,3 & 2,50 & 1,50 & 3 & 0,09 & 0,225 & 0,135 & 0,27 \\
\hline 0,3 & 1,80 & 0,60 & 5 & 0,09 & 0,162 & 0,054 & 0,45 \\
\hline 0,1 & 2,80 & 1,50 & 12 & 0,01 & 0,028 & 0,015 & 0,12 \\
\hline 0,1 & 0,60 & 0,50 & 1 & 0,01 & 0,006 & 0,005 & 0,01 \\
\hline 0,1 & 0,45 & 0,20 & 5 & 0,01 & 0,0045 & 0,002 & 0,05 \\
\hline \multirow[t]{3}{*}{0,2} & 12,00 & 5,00 & 6 & 0,04 & 0,48 & 0,2 & 0,24 \\
\hline & \multicolumn{3}{|c|}{$\sum$} & 1,45 & 5,04 & 4,086 & 9,83 \\
\hline & \multicolumn{4}{|c|}{$\mathrm{å}\left[\left(\mathrm{m}_{\mathrm{i} 1}{ }^{2}\right)^{*} \mathrm{X}_{\mathrm{j}]}\right] / \mathrm{a}\left(\mathrm{m}_{\mathrm{i1}}{ }^{2}\right.$} & 3,475862069 & 2,817931034 & 6,779310345 \\
\hline
\end{tabular}


Techno.COM, Vol. 19, No. 4, November 2020: 481-495

Tabel 9. Perhitungan Pusat Cluster Derajat Keanggotaan Ke-3

\begin{tabular}{|c|c|c|c|c|c|c|c|}
\hline \multicolumn{8}{|c|}{ PERHITUNGAN PUSAT CLUSTER } \\
\hline \multirow{2}{*}{$\begin{array}{l}\text { Derajat Keanggotaan Pada } \\
\text { Cluster Ke-3 }\end{array}$} & \multicolumn{3}{|c|}{ Data yang di Cluster } & \multirow{2}{*}{$\left(m_{i 1}\right)^{2}$} & \multirow{2}{*}{$\left(\mathrm{m}_{\mathrm{ii}}\right)^{2 *} \mathrm{X}_{1}$} & \multirow{2}{*}{$\left(\mathrm{m}_{\mathrm{il}}\right)^{2} * \mathrm{X}_{2}$} & \multirow{2}{*}{$\left(m_{i 1}\right)^{2} * X_{3}$} \\
\hline & $\mathrm{X} 1$ & $\mathrm{X} 2$ & $\mathrm{X} 3$ & & & & \\
\hline 0,5 & 1,00 & 0,50 & 4 & 0,25 & 0,25 & 0,125 & 1 \\
\hline 0,5 & 2,50 & 1,95 & 2 & 0,25 & 0,625 & 0,4875 & 0,5 \\
\hline 0,1 & 6,00 & 5,00 & 12 & 0,01 & 0,06 & 0,05 & 0,12 \\
\hline 0,1 & 0,24 & 0,20 & 2 & 0,01 & 0,0024 & 0,002 & 0,02 \\
\hline 0,1 & 1,25 & 1,00 & 3 & 0,01 & 0,0125 & 0,01 & 0,03 \\
\hline 0,3 & 2,34 & 10,00 & 3 & 0,09 & 0,2106 & 0,9 & 0,27 \\
\hline 0,1 & 1,75 & 0,80 & 8 & 0,01 & 0,0175 & 0,008 & 0,08 \\
\hline 0,2 & 9,88 & 5,00 & 4 & 0,04 & 0,3952 & 0,2 & 0,16 \\
\hline 0,2 & 2,43 & 1,10 & 7 & 0,04 & 0,0972 & 0,044 & 0,28 \\
\hline 0,6 & 2,50 & 1,50 & 3 & 0,36 & 0,9 & 0,54 & 1,08 \\
\hline 0,2 & 1,80 & 0,60 & 5 & 0,04 & 0,072 & 0,024 & 0,2 \\
\hline 0,3 & 2,80 & 1,50 & 12 & 0,09 & 0,252 & 0,135 & 1,08 \\
\hline 0,8 & 0,60 & 0,50 & 1 & 0,64 & 0,384 & 0,32 & 0,64 \\
\hline 0,7 & 0,45 & 0,20 & 5 & 0,49 & 0,2205 & 0,098 & 2,45 \\
\hline \multirow[t]{3}{*}{0,4} & 12,00 & 5,00 & 6 & 0,16 & 1,92 & 0,8 & 0,96 \\
\hline & \multicolumn{3}{|c|}{$\Sigma$} & 2,49 & 5,4189 & 3,7435 & 8,87 \\
\hline & \multicolumn{4}{|c|}{$\mathrm{å}\left[\left(\mathrm{m}_{\mathrm{i} 1}{ }^{2}\right) * \mathrm{X}_{\mathrm{ij}}\right] / \mathrm{a}\left(\mathrm{m}_{\mathrm{i1}}{ }^{2}\right)$} & 2,17626506 & 1,503413655 & 3,562248996 \\
\hline
\end{tabular}

Maka pusat Claster ke-k: $\mathrm{V}_{k j}$ pada setiap cluster yaitu pada tabel 10,

Tabel 10. Hasil Pusat Cluster

$\mathrm{V}=\quad$\begin{tabular}{|c|c|c|}
\hline \multicolumn{3}{|c|}{ HASIL PUSAT CLUS TER $(V)$} \\
\hline 3,1966327 & 2,152891156 & 5,136054 \\
\hline 3,4758621 & 2,817931034 & 6,77931 \\
\hline 2,1762651 & 1,503413655 & 3,562249 \\
\hline
\end{tabular}

5. Setelah hasil pusat claster diperoleh maka langkah selanjutnya hitung fungsi objektif pada iterasi ke-t, hasil perhitungan dapat dilihat pada tabel 11.

Tabel 11. Perhitungan Fungsi Objektif Iterasi ke-1

\begin{tabular}{|c|c|c|c|c|c|c|}
\hline \multicolumn{7}{|c|}{ PENGHITUNGAN FUNGSI O B JEKTIF } \\
\hline \multicolumn{3}{|c|}{ Kuadrat Derajat Keanggotaan data ke-i } & {$\left[\sum_{j=1}^{6}\left(x_{i j}-V_{1 j}\right)^{2}\right]\left(\mu_{i 1}\right)^{2}$} & {$\left[\sum_{j=1}^{6}\left(X_{i j}-V_{2 j}\right)^{2}\right]\left(\mu_{i 2}\right)^{2}$} & {$\left[\sum_{j=1}^{6}\left(X_{i j}-V_{3 j}\right)^{2}\right]\left(\mu_{i 3}\right)^{2}$} & \multirow[t]{2}{*}{$\mathrm{L} 1+\mathrm{L} 2+\mathrm{L} 3$} \\
\hline $\mathrm{m}_{\mathrm{i} 1}{ }^{2}$ & $\mathrm{~m}_{\mathrm{i} 2}{ }^{2}$ & $\mathrm{~m}_{\mathrm{i} 3}{ }^{2}$ & L1 & L2 & L3 & \\
\hline 0,04 & 0,09 & 0,25 & 0,353914553 & 0,76909053 & 0,103282576 & 1,22628766 \\
\hline 0,01 & 0,16 & 0,25 & 0,103612992 & 0,245474184 & 0,027448656 & 0,376535832 \\
\hline 0,09 & 0,36 & 0,01 & 5,677078153 & 3,454946797 & 8,823843627 & 17,95586858 \\
\hline 0,64 & 0,01 & 0,01 & 14,32979062 & 25,70635111 & 5,048724137 & 45,08486587 \\
\hline 0,49 & 0,04 & 0,01 & 4,743819947 & 11,04583572 & 0,699482939 & 16,48913861 \\
\hline 0,16 & 0,09 & 0,09 & 10,69978643 & 10,74487743 & 11,60558601 & 33,05024988 \\
\hline 0,16 & 0,25 & 0,01 & 1,940039166 & 1,366516604 & 3,259220263 & 6,565776033 \\
\hline 0,36 & 0,04 & 0,04 & 19,4630571 & 19,2596305 & 25,83549865 & 64,55818625 \\
\hline 0,16 & 0,16 & 0,04 & 0,827295765 & 0,655010949 & 1,927240954 & 3,409547668 \\
\hline 0,01 & 0,09 & 0,36 & 0,054742924 & 0,169724357 & 0,004209399 & 0,22867668 \\
\hline 0,25 & 0,09 & 0,04 & 1,095141129 & 2,723419263 & 0,756214894 & 4,574775286 \\
\hline 0,36 & 0,01 & 0,09 & 17,17103996 & 10,6017596 & 25,77049162 & 53,54329118 \\
\hline 0,01 & 0,01 & 0,64 & 0,265814965 & 0,47043815 & 0,100565704 & 0,836818819 \\
\hline 0,04 & 0,01 & 0,49 & 0,455051424 & 0,767013979 & 0,269840247 & 1,491905649 \\
\hline 0,16 & 0,04 & 0,16 & 13,81627318 & 12,48474833 & 18,34792227 & 44,64894378 \\
\hline \multicolumn{6}{|c|}{ Fungsi Objective $=$ å } & 294,0408678 \\
\hline
\end{tabular}

Berdasarkan tabel 11 maka hasil perhitungan fungsi objektif menjadi ;

$$
P_{1}=\sum_{i=1}^{30} \sum_{k=1}^{5}\left(\left[\sum_{j=1}^{4}\left(X_{i j}-V_{k j}\right)^{2}\right]\left(\mu_{i k}\right)^{2}\right)=294,0408678
$$


6. Hitung perubahan matriks partisi dan perubahan matrik partisi $U$, menggunakan rumus 4 sehingga diperoleh hasil perubahan matrik partisi yang terdapat pada tabel 12 .

Tabel 12. Perubahan Matrik Partisi dan Perubahan Matriks Partisi U

\begin{tabular}{|c|c|c|c|c|c|c|}
\hline \multicolumn{7}{|c|}{ MATRIKS PARTISI U } \\
\hline$\sum_{j=1}^{6}\left(X_{i j}-V_{1 j}\right)^{2}$ & $\sum_{j=1}^{6}\left(X_{i j}-V_{2 j}\right)^{2}$ & $\sum_{j=1}^{6}\left(X_{i j}-V_{3 j}\right)^{2}$ & $\sum_{k=1}^{3}\left[\sum_{j=1}^{6}\left(X_{i j}-V_{k j}\right)^{2}\right]$ & $\mathrm{m}_{\mathrm{i} 1}$ & $\mathrm{~m}_{\mathrm{i} 2}$ & $\mathrm{~m}_{\mathrm{i3}}$ \\
\hline$\overline{\mathrm{L} 1}$ & $\mathrm{~L} 2$ & L3 & $\mathrm{LT}=\mathrm{L} 1+\mathrm{L} 2+\mathrm{L} 3$ & $\mathrm{~L} 1 / \mathrm{LT}$ & $\mathrm{L} 2 / \mathrm{LT}$ & $\mathrm{L} 3 / \mathrm{LT}$ \\
\hline 0,113021631 & 0,052009482 & 0,38728701 & 0,552318123 & 0,2046314 & 0,094165807 & 0,701202793 \\
\hline 0,096512993 & 0,040737481 & 0,364316562 & 0,501567037 & 0,192422919 & 0,081220412 & 0,726356669 \\
\hline 0,015853225 & 0,026049605 & 0,010199637 & 0,052102467 & 0,304270148 & 0,499968744 & 0,195761108 \\
\hline 0,044662202 & 0,024896571 & 0,1267647 & 0,196323473 & 0,227492928 & 0,126814032 & 0,645693039 \\
\hline 0,103292285 & 0,044360609 & 0,700517443 & 0,848170336 & 0,121782477 & 0,052301533 & 0,82591599 \\
\hline 0,014953569 & 0,014890817 & 0,013786465 & 0,043630851 & 0,342729267 & 0,341291 & 0,315979733 \\
\hline 0,082472562 & 0,117086027 & 0,049091496 & 0,248650085 & 0,331681213 & 0,470886736 & 0,197432052 \\
\hline 0,01849658 & 0,018691947 & 0,013934316 & 0,051122844 & 0,361806563 & 0,365628084 & 0,272565353 \\
\hline 0,193401208 & 0,244270726 & 0,083020237 & 0,52069217 & 0,371430989 & 0,469126943 & 0,159442068 \\
\hline 0,18267201 & 0,058919063 & 2,37563606 & 2,617227133 & 0,06979601 & 0,022512017 & 0,907691973 \\
\hline 0,22828108 & 0,091796369 & 0,330593859 & 0,650671308 & 0,350839321 & 0,141079479 & 0,5080812 \\
\hline 0,020965533 & 0,033956627 & 0,013969466 & 0,068891626 & 0,304326287 & 0,492899201 & 0,202774511 \\
\hline 0,037620154 & 0,021256779 & 0,099437478 & 0,158314412 & 0,237629372 & 0,13426939 & 0,628101238 \\
\hline 0,087902153 & 0,052150288 & 0,148235856 & 0,288288298 & 0,304910584 & 0,180896306 & 0,51419311 \\
\hline 0,011580547 & 0,012815637 & 0,008720333 & 0,033116517 & 0,349690968 & 0,38698625 & 0,263322782 \\
\hline
\end{tabular}

7. Cek kondisi berhenti:

1. Jika $\mathrm{t}>$ max iter maka berhenti

2. Jika tidak, $\mathrm{t}=\mathrm{t}+1$, ulangi langkah ke-4

$$
\begin{array}{lll}
\mathrm{P} 1 & = & 294,0408678 \\
\mathrm{P} 0 & = & 0 \\
|\mathrm{P} 1-\mathrm{P} 0| & = & 294,0408678
\end{array}
$$

Karena nilai $\mathrm{P}_{1}-\mathrm{P}_{0}>$ nilai error $(0,1)$ maka proses dilanjutkan pada iterasi ke-2,3,4...n sampai nilai eror stabil atau dibawah 0,1 dan prosesnya diulangi dari langkah ke-4. Untuk kasus ini berhenti sampai iterasi ke-23, maka dapat ditarik kesimpulan bahwa hasil penerapan metode Fuzzy C-Means Clustering yaitu;

a. Matriks partisi $U$ akhir 
Tabel 13. Matriks Partisi U Akhir Iterasi ke-23

\begin{tabular}{|c|c|c|}
\hline \multicolumn{3}{|c|}{ MATRIKS PARTISI U } \\
\hline $\mathbf{U}=0,008306179$ & 0,019071973 & 0,972621848 \\
\hline 0,043378187 & 0,050676798 & 0,905945015 \\
\hline 0,181213232 & 0,711485142 & 0,107301626 \\
\hline 0,024478643 & 0,040305874 & 0,935215483 \\
\hline 0,000800005 & 0,001415884 & 0,997784112 \\
\hline 0,346923019 & 0,279720868 & 0,373356113 \\
\hline 0,063743431 & 0,652295694 & 0,283960875 \\
\hline 0,975847919 & 0,012139316 & 0,012012765 \\
\hline 0,077507415 & 0,501586369 & 0,420906215 \\
\hline 0,019834958 & 0,028944793 & 0,951220249 \\
\hline 0,031961108 & 0,091027434 & 0,877011458 \\
\hline 0,03436493 & 0,913766457 & 0,051868614 \\
\hline 0,041153416 & 0,05645215 & 0,902394434 \\
\hline 0,032293785 & 0,097741257 & 0,869964958 \\
\hline 0,929694522 & 0,040613443 & 0,029692035 \\
\hline
\end{tabular}

Data Matriks partisi U akhir digunakan untuk menentukan masing-masing cluster pada setiap data. Maka dari matriks partisi U tersebut didapatkan hasil cluster yang ada di tabel 14.

Tabel 14. Derajat Keanggotaan Tiap Data Pada Setiap Cluster dengan FCM

\begin{tabular}{|c|c|c|c|c|}
\hline \multirow{2}{*}{ Nama Usaha } & \multicolumn{2}{|c|}{ Derajat keanggotaan tiap data pada setiap cluster dengan FCM } & \multirow{2}{*}{$\begin{array}{c}\text { Data Cenderung Masuk ke Cluster } \\
\text { dengan Derajat keangotaan }\end{array}$} \\
\cline { 2 - 4 } & 1 & 2 & 3 & 0,972621848 \\
\hline Perdagangan TBS & 0,008306179 & 0,019071973 & 0,972621848 & 0,905945015 \\
\hline Komawar & 0,043378187 & 0,050676798 & 0,905945015 & 0,711485142 \\
\hline Prima Motor & 0,181213232 & 0,711485142 & 0,107301626 & 0,935215483 \\
\hline Ikan Hiyas & 0,024478643 & 0,040305874 & 0,935215483 & 0,997784112 \\
\hline Fres Roo & 0,000800005 & 0,001415884 & 0,997784112 & 0,373356113 \\
\hline Toko Pincuran & 0,346923019 & 0,279720868 & 0,373356113 & 0,652295694 \\
\hline Toko Abah Elektronik & 0,063743431 & 0,652295694 & 0,283960875 & 0,975847919 \\
\hline Toko Murni Diesel & 0,975847919 & 0,012139316 & 0,012012765 & 0,501586369 \\
\hline CV. Wijaya Enginering & 0,077507415 & 0,501586369 & 0,420906215 & 0,951220249 \\
\hline Toko Nasco & 0,019834958 & 0,028944793 & 0,951220249 & 0,877011458 \\
\hline Doa Ibu & 0,031961108 & 0,091027434 & 0,877011458 & 0,913766457 \\
\hline Apotek Mitra Harum & 0,03436493 & 0,913766457 & 0,051868614 & 0,902394434 \\
\hline Rental Mobil & 0,041153416 & 0,05645215 & 0,902394434 & 0,869964958 \\
\hline Toko Rental & 0,032293785 & 0,097741257 & 0,869964958 & 0,929694522 \\
\hline Cv. Dua Putri & 0,929694522 & 0,040613443 & 0,029692035 & \\
\hline
\end{tabular}

Dari tabel 14 dapat dilihat hasil data pada setiap cluster lebih cendrung mendekati nilai rata-rata validasinya hampir mendekati angka 1 , pada tabel 14 ditandai dengan angka berwarna merah, Berdasarkan tabel 14, maka hasil cluster usaha mikro, cluster usaha kecil dan cluster usaha menengah berdasarkan data dapat dilihat pada tabel 15 berikut: 
Tabel 15. Hasil Cluster Usaha Mikro

\begin{tabular}{|l|c|}
\hline \multicolumn{1}{|c|}{ Nama Usaha } & Cluster \\
\hline Perdagangan TBS & Usaha Mikro \\
\hline Komawar & Usaha Mikro \\
\hline Ikan Hiyas & Usaha Mikro \\
\hline Fres Roo & Usaha Mikro \\
\hline Toko Pincuran & Usaha Mikro \\
\hline Toko Nasco & Usaha Mikro \\
\hline Doa Ibu & Usaha Mikro \\
\hline Rental Mobil & Usaha Mikro \\
\hline Toko Rental & Usaha Mikro \\
\hline
\end{tabular}

\begin{tabular}{|l|c|}
\hline \multicolumn{1}{|c|}{ Nama Usaha } & Cluster \\
\hline Prima Motor & Usaha Kecil \\
\hline Toko Abah Elektronik & Usaha Kecil \\
\hline CV. Wijuga Enginering & Usaha Kecil \\
\hline Apotek Mitra Harum & Usaha Kecil \\
\hline
\end{tabular}

\begin{tabular}{|l|c|}
\hline \multicolumn{1}{|c|}{ Nama Usaha } & Cluster \\
\hline Toko Murni Diesel & Usaha Menegah \\
\hline Cv. Dua Putri & Usaha Menegah \\
\hline
\end{tabular}

Dari tabel 15, dapat dilihat kecendrungan data-data nama usaha dan hasil pengelompokan jenis usaha sesuai dengan Undang-Undang No. 20 Tahun 2008.

\subsection{Implementasi Sistem}

Bahasa pemograman yang digunakan untuk membangun aplikasi data mining untuk clustering UKM ini adalah bahasa php dan database mysql. Tampilan awal dari aplikasi ini berupa halaman login, pengguna dapat memasukkan username dan password yang valid agar dapat mengakses aplikasi ini, tampilan halaman login dapat dilihat pada gambar 2.

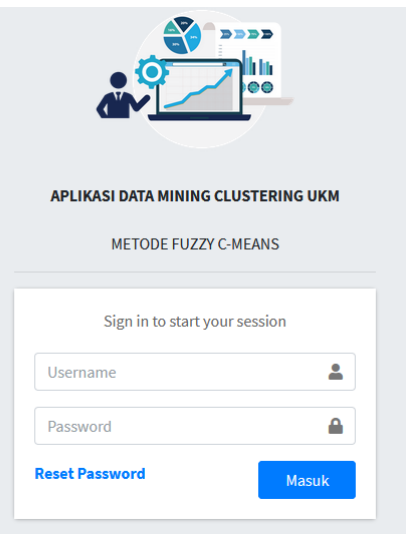

Gambar 3. Halaman Login User

Setelah username dan password valid, maka pengguna dapat mengakses halaman dashboard dan menu-menu yang tersedia seperti pada gambar 4 .

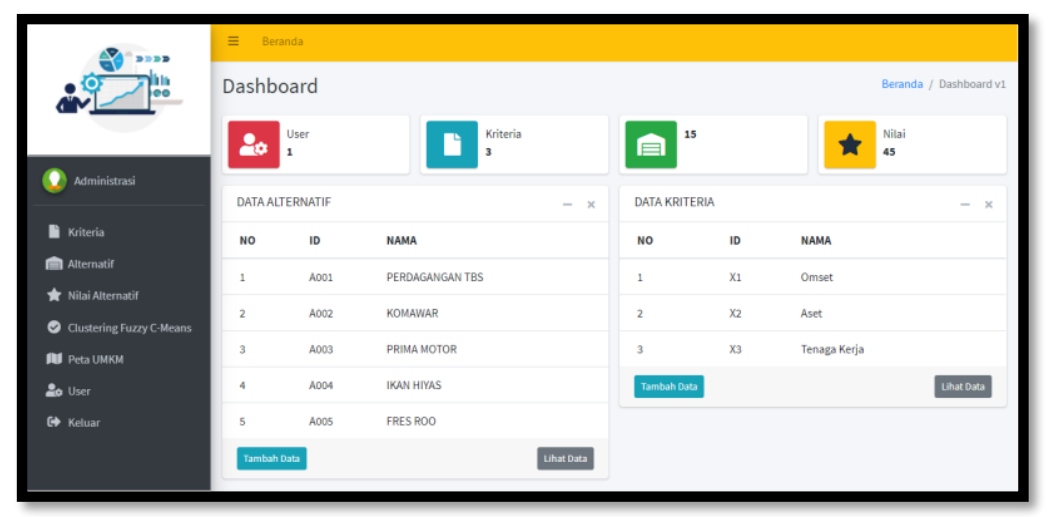

Gambar 4. Tampilan Setelah Login / Dashboard 
Pada halaman ini admin dapat memanipulasi data, mulai dari menambah data, menghapus, dan meng-edit data, menu-menu yang tersedia pada dashboard ini yaitu menu kriteria, menu alternatif, nilai alternatif, menu perhitungan FCM, peta persebarana UKM, menu user dan keluar. Untuk tampilan perhitungan menggunakan Fuzzy C-Means Clustering dapat dilihat pada gambar 5 .

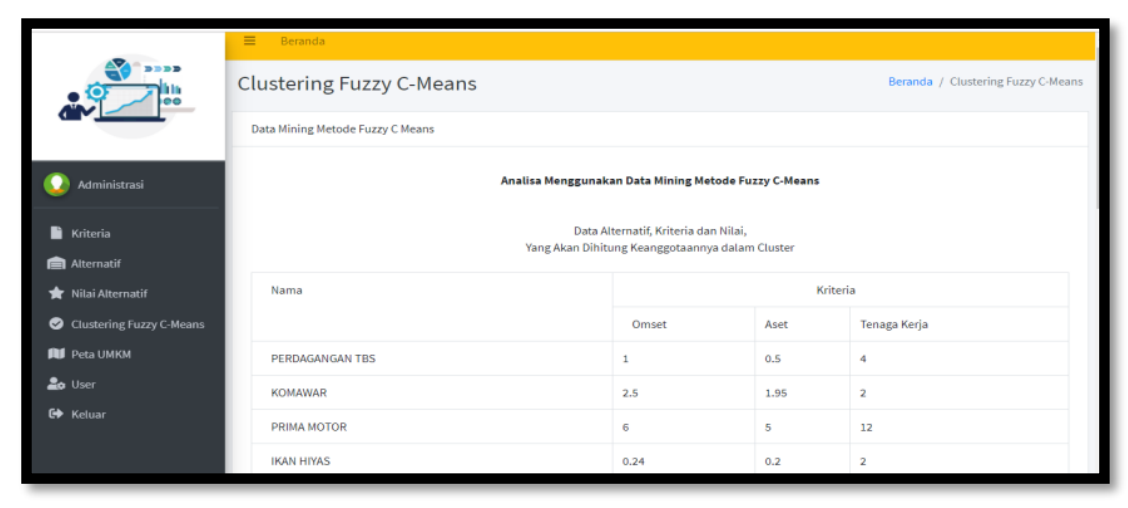

Gambar 5. Tampilan Proses Penerapan Algoritma Fuzzy C-Means Clustering

Sedangkan untuk tampilan pesebaran UKM dapat dilihat pada gambar 5, pesebaran tersebut didapat dari data yang sudah dinputkan kedalam metode Fuzzy C-Means Clustering sehingga hasilnya berupa sebuah peta persebaran UKM lengkap dengan jenis pengelompokan UMKM.

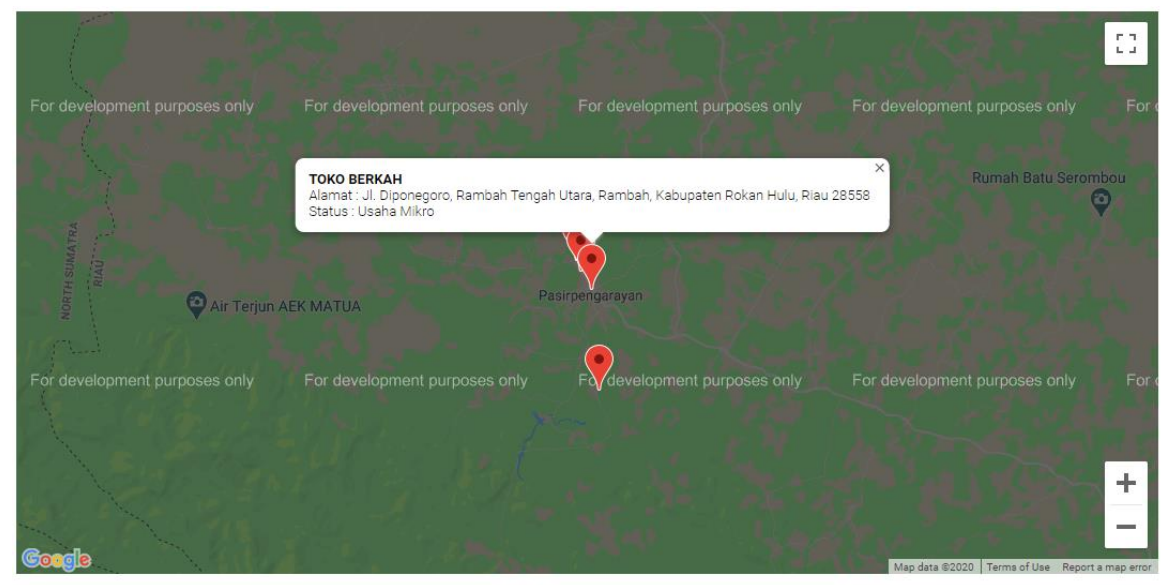

Gambar 6. Peta Persebaran UKM Menggunakan Metode Fuzzy C-Means Clustering

\subsection{Pengujian Sistem}

Berdasarkan hasil pengujian yang telah dilakukan terhadap aplikasi yang diimplementasikan menggunakan Fuzzy C-Means Clustering ini, serta menggunakan data uji sebanyak 150 data maka dapat disimpulkan bahwa nilai validasi dan derajat keanggotaan akhir yang terbentuk dari setiap data yang diklaster nilai rata-ratanya hampir mendekati angka 1 , hal tersebut menunjukkan bahwa Fuzzy C-Means Clustering memiliki tingkat akurasi yang tinggi sebesar 80-95\%, untuk lebih jelasnya dapat dilihat pada tabel 16 . 
Tabel 16. Pengujian Nilai Validasi dari Derajat Keanggotaan Akhir Berdasarkan Jumlah Data

\begin{tabular}{|c|c|c|}
\hline \multicolumn{2}{|c|}{ Hasil Akhir Derajat Keanggotaan Tiap Data FCM } & $\begin{array}{c}\text { Persentase } \\
\text { Validasi }\end{array}$ \\
\hline Jumlah Data Uji & Derajat Keanggotaan Mendekati Angka 1 & $(\%)$ \\
\hline 15 data & 14 data & 93 \\
\hline 50 data & 45 data & 90 \\
\hline 100 data & 84 data & 84 \\
\hline 115 data & 115 data & 89,5 \\
\hline 121 data & 108 data & 89 \\
\hline 150 data & 143 & 95 \\
\hline
\end{tabular}

Sedangkan untuk pengujian kepada sistem yang telah dibangun menggunakan pengujian UAT (User Acceptance Test) kepada user, jenis pengujian ini dapat digunakan sebagai bukti apakah aplikasi yang diimplementasikan sudah diterima dengan baik dan sudah mengatasi masalah sesuai dengan kebutuhan user. Hasil pengujian menunjukkan bahwa aplikasi pengelompokan jenis UKM sudah dapat diterima dengan baik oleh user pada instansi terkait dan dapat memberikan kemudahan bagi admin untuk dapat merekap dan mengelompokkan jenis UKM yang ada di Kabupaten Rokan Hulu dengan tepat serta dilengkapi dengan peta persebaran UKM.

\section{KESIMPULAN DAN SARAN}

Berdasarkan hasil implementasi dan pengujian sistem yang telah dilakukan, maka dapat disimpulkan bahwa penerapan metode Fuzzy C-Means Clustering mampu mengelompokkan jenis UKM sesuai dengan ketentuan undang-undang No. 20 Tahun 2008, dengan menggunakan variabel berupa omset, asset dan jumlah tenaga kerja dan hasil uji coba dari sejumlah data yang diinputkan menunjukkan bahwa metode Fuzzy C-Means Clustering mempunyai nilai validasinya rata-rata hampir mendekati angka 1, hal tersebut menunjukkan bahwa Fuzzy C-Means Clustering memiliki tingkat akurasi yang tinggi sebesar $90 \%$. Untuk penelitian selanjutnya disarankan agar dapat membandingkan metode Fuzzy C-Means Clustering dengan metode lain untuk mendapat pola validasi yang berbeda. Diharapkn dengan adanya perbandingan tersebut dapat memberikan gambaran tingkat akurasi, validasi dan keefektifan dari suatu metode Fuzzy C-Means Clustering.

\section{UCAPAN TERIMA KASIH}

Terima kasih penulis ucapkan kepada Direktorat Riset dan Pengabdian Masyarakat Direktorat Jenderal Riset dan Pengembangan Kementerian Riset, Teknologi, dan Pendidikan Tinggi yang telah mendanai Penelitian Dosen Pemula ini.

\section{DAFTAR PUSTAKA}

[1] Oki, 2016, Investasi UKM Terus Meningkat di Kabupaten Rokan Hulu. Topriau.com.

[2] Luthfi, E. T. (2007, November). Fuzzy C-Means untuk Clustering Data (studi kasus: data performance mengajar dosen). In Seminar Nasional Teknologi (Vol. 2007, pp. 1-7).

[3] Abdy, M. (2018). Pengklasteran dengan Algoritma Fuzzy C-Means. Jurnal Matematika, Statistika dan Komputasi, 12(1), 30-35.

[4] Kusuma, D. T., \& Agani, N. (2015). Prototipe Komparasi Model Clustering Menggunakan Metode K-Means Dan FCM untuk Menentukan Strategi Promosi: Study Kasus Sekolah Tinggi Teknik-PLN Jakarta. Jurnal TICom, 3(3), 93460.

[5] Sutoyo, M. N., \& Sumpala, A. T. (2015). Penerapan Fuzzy C-Means untuk Deteksi Dini Kemampuan Penalaran Matematis. Scientific Journal of Informatics, 2(2), 129-135. 
[6] DewiAstria, D., \& Suprayogi, S. (2017). Penerapan Algoritma Fuzzy C-Means Untuk Clustering Pelanggan Pada CV. Mataram Jaya Bawen. Jurnal Eksplora Informatika, 6(2), 169-187.

[7] Ferdiansyah, R., Efendi, R., \& Susilo, B. (2018). Rancang Bangun Aplikasi Klasifikasi Usaha Mikro Home Industry Ikan Kering Dengan Algoritme Fuzzy C-Means Clustering di Daerah Pesisir Kota Bengkulu. Rekursif: Jurnal Informatika, 6(2).

[8] Ramadhan, A., Efendi, Z., \& Mustakim, M. (2017, May). Perbandingan K-Means dan Fuzzy C-Means untuk Pengelompokan Data User Knowledge Modeling. In Seminar Nasional Teknologi Informasi Komunikasi dan Industri (pp. 219-226).

[9] Rustiyan, R., \& Mustakim, M. (2018). Penerapan Algoritma Fuzzy C Means untuk Analisis Permasalahan Simpanan Wajib Anggota Koperasi. Jurnal Teknologi Informasi Dan Ilmu Komputer, 5(2), 171-176.

[10] Kusumadewi, Sri, Purnomo Hari. Aplikasi Logika Fuzzy. Graha Ilmu. Yogyakarta; 2010.

[11] Alexander F.K. Sibero. Web programming power pack. MediaKom. Yogyakarta; 2013.

[12] Betha Sidik and I. M. E. I. P. Husni. Pemrograman Web dengan PHP, Bandung: Informatika. 2012. 